\title{
A Longitudinal Study on the Perceived Roles of IT and the Corporate IT Function with Influences on CIOs' Work Equilibria in a Media Company
}

\author{
Tomi Dahlberg \\ Turku School of Economics at the \\ University of Turku \& Aalto University \\ School of Business, Finland \\ tomi.dahlberg@utu.fi
}

\author{
Päivi Hokkanen \\ Turku School of Economics at the \\ University of Turku, Finland \\ spjhok@utu.fi
}

\author{
Mike Newman \\ Manchester Business School, University \\ of Manchester, UK \& Turku School of \\ Economics at the University of Turku \\ mike.newman@mbs.ac.uk
}

\begin{abstract}
Our article investigates factors impacting IT executives' equilibria of $\mathrm{CIO}$ work. We used the interview data collection method in a media company. Interviews revealed that the roles of IT and the corporate IT function were seen differently at three levels - social groups - of the company. During the years 2010-2016 our case company experienced several business interruptions. We investigated how two of them and the perceived roles of IT and the corporate IT function impacted three IT executives' equilibria of $\mathrm{CIO}$ work by using the punctuated equilibrium model. Moreover, we used constructs from Granovetter's social network theory to better understand why their perceptions and equilibria differed. The punctuated equilibrium model together with the constructs of the social network theory proved valuable in understanding the changes in the role perceptions and the equilibria of $\mathrm{CIO}$ work.
\end{abstract}

\section{Introduction}

We interviewed the CIO of a telecom company for another study. He told us that the roles of IT and the corporate IT function were understood differently in his company. According to him, what was generally understood as IT and managed by the corporate IT function, and what was understood as business technology and managed by the network business unit were technologically almost identical. These technologies were purchased from the same vendors, stood side by side in the data centres of the company and were operated with the same operating system (OS) management software. Yet, the approaches to investments were different. The corporate IT function was required to craft detailed business and investment plans, whereas the (typically larger) investments of the network business unit were usually accepted with a lighter procedure as business necessities. Furthermore, some executives regarded the corporate IT as a support function ("necessary evil") and understood IT narrowly as the technology that the corporate IT function managed. At the other extreme were executives, who thought that the IT function should be a business unit ("develop strategic advantages") and understood IT broadly as the combination of corporate IT and business technology. The CIO explained that it took several years for the executives of the company to grasp that the company could achieve cost savings, operational synergies and other benefits by managing both "corporate IT" and "business technology" as the deployment of IT in business, and that IT and the IT function may appear in several roles depending on its use context.

The interviewed CIO's story led us to ask; do similar different perceptions appear in other organizations, and, if so, how could these perceptions and their changes be described? This is our research problem. Prior research has, indeed, reported during several decades [e.g. 1, 18, 23, 29] that divergences in values, beliefs, education and experience [17] produce variations in IT perceptions. Considerations discussed above induced the following two questions. How do differences in perceptions regarding the roles of IT and the corporate IT function within one organization influence the work of IT executives? What social mechanisms contribute to (dis)agreeing within one organization on the roles of IT and the corporate IT function?

The purpose of the present study is to examine these questions with a longitudinal case study conducted within a media company during the turbulent years of 2010-2016. During this period our case company executed eight M\&A transactions and established new business areas by combining M\&A transactions with greenfield operations. We investigated how significant business strategy induced interruptions changed the work of three ITleaders and how perceptions about the roles of IT and corporate IT function are related to those changes. We interviewed the CIO to understand how her work had changed. Besides the $\mathrm{CIO}$, also involved in our 
study are the CFO as the boss of the CIO, and the IT manager reporting to the CIO. For an interruption we understand it to be "an occasion when something stops something happening for a short period" [6]. An example would be the inability to continue work "as is" after an M\&A transaction.

In the method we follow, we label interruptions as punctuations [14]. The applied punctuated equilibrium model is an episodic change model, where relatively long periods of stability are interrupted by relatively short periods of revolutionary changes [14]. The idea is that there is an aspiration to reach equilibrium between the factors that constitute one's work. Punctuation interrupts an existing equilibrium and begins a process of change to find a new equilibrium. Our objective is to demonstrate that the punctuated equilibrium model [14] with its graphical notation [28] provides a useful perspective for viewing changes in the work of IT executives [36] after punctuations. Our other objective is to augment the punctuated equilibrium model with social network theory constructs $[15,17]$. Social network constructs are used to better understand and describe how social ties and other social mechanisms suggested by the theory influence detected changes in work equilibria following punctuations - including the influences of differences in perceptions about the roles of IT and the corporate IT function. In summary, our research questions are:

- How do business disruptions and perceptions about the roles of IT and the corporate IT function impact the work IT executives? and

- Are social network theory constructs useful increments to the punctuated equilibrium model that help to explain how social mechanisms influence the equilibria of work and differences in perceptions about the roles of IT and the corporate IT function?

The rest of the article is organized as follows. First, as the theoretical background, we depict how evolutions in business-IT alignment research have changed perspectives about the roles of IT and the corporate IT function, how the punctuated equilibrium model describes changes in the work after punctuations, and how the social network theory constructs explain social mechanisms related to such changes. We then explicate the research methods used in our case study. Next we report the results of the study and end the article with a discussion of its contributions and our conclusions.

\section{Theoretical Background}

\subsection{Business-IT alignment and the role of IT}

With business and IT/IS strategies, organizations adapt to their business environments and set strategic objectives [22]. Research on the alignment of business and IT/IS strategies as well as business and IT/IS structures and processes have been topical issues in IS research during the last 40 years [e.g. 24, $29,19,7,13,8]$. In the present article, we look at this research from the perspective of how the roles of IT and the corporate IT function have been described. The framework proposed by McFarlan et al. in 1983 [29, Figure 1], addresses this issue and has been very influential. It may still influence the minds of some (business) executives, since some of them have received education and have started their careers when the deployment of IT was significantly lesser than today. According to prior research executives' attitudes towards and beliefs about IT and the IT function differ remarkably. For example, still in 2005 Kaarst-Brown [23] reported that IT and the relation between business and IT function was perceived as follows: necessary evil, IT is support not a partner, IT rules!, business can do it better, or equal partners. The important point for our article is that the roles of IT and the corporate IT are perceived in many ways.

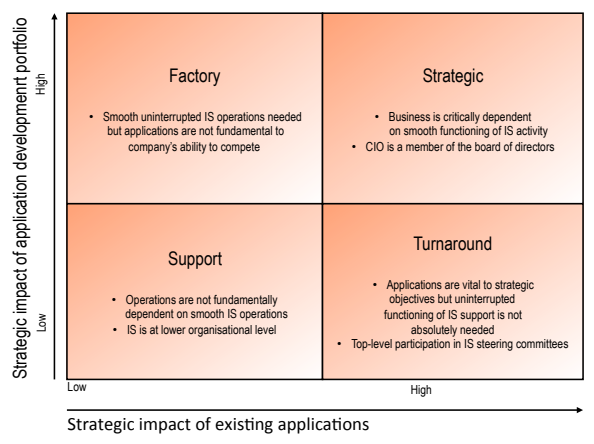

\section{Figure 1. Strategic impact of IS activities on a company from McFarlan et al. [29]}

The previously defined role of IT in business and the purpose of the corporate IT function's activities were matched in Figure 1 [29]. The proposition was that the corporate IT function should execute activities, which are in line with the perceived role of IT in business. That the focus in the activities executed and the services provided by the corporate IT function can be defined unambiguously, has remained a strong theme in research on how to organize the corporate IT function [e.g. 1, 18].

In 1983, when the deployment of IT was nascent compared to today, it might have been possible to describe the role of IT in an organization with the kind of framework shown in Figure 1. Yet, after that 
the deployment of IT has exploded, especially after the millennium change. For example, Hilbert and Lopez [20] estimated that in 2000 the creation and storing of analogue data was three times bigger than that of digital data. In 2002-2003 the proportions were equal and in 2011 over $99 \%$ was digital.

Rapid proliferation in the deployment of IT has happened in so-called "business IT". For example, the US-based Gartner Inc. estimated in 2012 that the proportion of IT investments outside of the traditional corporate IT functions would grow to $90 \%$ of all investments in technology by the year 2020 from the proportion of $20 \%$ two decades earlier and $80 \%$ in 2012 [12]. According to Gartner Inc. much of this change "is being driven by the digitization of companies' revenue and services" (ibid.).

Digitalisation is often defined and understood as the integration of digital technologies into everyday life by the digitization of everything that can be digitized [5]. IT intensive industries, media industry as an example, are expected to lead the way in digitalisation. Product digitization and digitalisationenabled transformation of business describes the last two decades of the media industry. It has changed the industry's products [31], value chains and market structures [33, 10]. Media industry products and services using digital formats are produced and consumed increasingly. In addition to new digitalonly products, traditional versions of printed products have been replaced by digitized versions partly or even entirely. Furthermore, the world-wide-web, ebusiness and digital platforms have transformed the production, logistics and delivery channels of the media industry. New actors such as Amazon, Apple, Google and telecom operators, to name but a few, have entered media industry markets. This has further accelerated changes in the modus operandi of the media industry value chains and market structures [27]. Many traditional media industry organizations are struggling with lower revenues and margins due to this rapid growth in digital products and services. As a consequence, to just simply survive, these media organizations have been forced to change their business strategies in order to improve their performance and productivity [30]. The digitalisation of the media industry depicts also the business strategy and the alignment of business and IT in our case company. The rationale of the company's business strategy is to cover the whole value chain of the industry: to exploit the opportunities of product digitization, new digital-only products and digitalisation-enabled industry transformation.

These developments have impacted also the business-IT alignment research. The traditional approach has been to develop business strategy first and IT/IS strategy then by aligning the IT/IS strategy to an already approved business strategy. The digital strategy concept [3] challenges the traditional approach by placing business and IT at the same level. The claim of digital business strategy is that the alignment concept has to be reconsidered since IT is the strategy. Consequently, IT and business together constitute the elements of a single digital strategy. The question, is this really the case, is identified as one of the key future research topics in business-IT alignment research [13]. For our research the implication is that there could be different perceptions about the role of IT and the corporate IT function.

\subsection{The punctuated equilibrium model}

We use the punctuated equilibrium model to describe how major change events, that is, business interruptions, punctuations, impact the work of individuals. The punctuated equilibrium model uses Leavitt's model as an organizational diagnostic model to describe work transformations after punctuations. A transformation may be incremental where change is convergent and evolutionary, i.e. continuous, incremental and cumulative [28]. In line with previous work such as Orlikowski [34], Sabherwal et al. [36], and Lyytinen and Newman [28], we suggest that a transformation may also contain critical event changes, where the change itself is radical, revolutionary, and often sudden. Such critical events break the evolutionary and incremental nature of the on-going work evolution and are thus interruptive. Interruptions are sociotechnical [e.g. 28]. Figure 2 shows the logic of the punctuated equilibrium model after an interruption.

The interrelationship of the two states (equilibria) in Figure 2 is explained through the deep structure construct, meaning the highly durable underlying order of states. The deep structure is defined [14, 39] as organization's 1) core values and beliefs, 2) strategy: products, markets, technology and competitive timing, 3) distribution of power, 4) organization structure and 5) organization's control systems. These factors are closely interrelated [37] but we think that they are not as durable and persistent as they used to be. For example, the current explosive pace of business digitalisation impacts technology and digital products so that these products change more frequently and rapidly than core values and beliefs. Furthermore, in contrast to Silva's and Hirschheim's suggestion [37], the logical consequence is that the adoption of a new technology does not necessarily impact the other factors in the deep structure. 


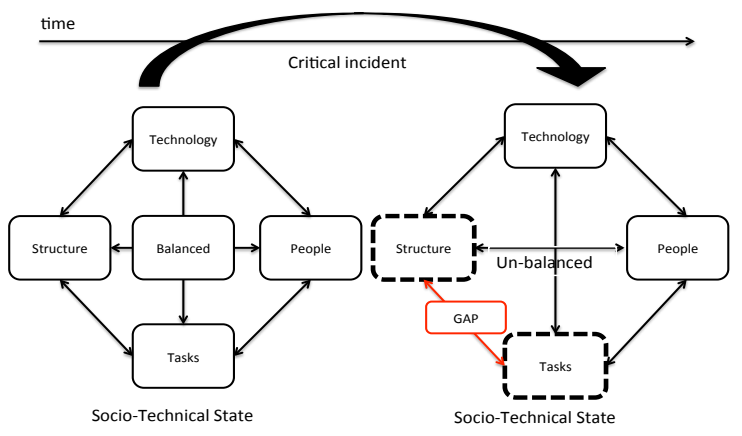

Figure 2. An event model for socio-technical change from Lyytinen and Newman [28]

\subsection{Social Network Theory constructs}

We use the constructs of Granovetter's [15-17] social network theory together with the punctuated equilibrium model. The aim is to better understand the social factors and mechanisms that illuminate how changes occur in the equilibria of work post interruptions. We considered institutional theory [e.g. 11] as an alternative. According to Eisenhardt [11], the idea of institutionalization is that legitimate organizational practices arise over time from imitative forces and firm traditions. In our case, due to repeated M\&As, it is possible that several imitative forces and traditions impact organizational practices at the same time. Continual business interruptions may not offer time needed for institutionalization to take place. Therefore we believe that the social network theory fits better in the context of our study.

Social networks affect the flow and the quality of information between individuals as well as the trust that other individuals will do the right things in a social network. The density of the network is the first construct we discuss. The denser the network the easier it is to enforce norms in the network, i.e. shared ideas about proper ways to behave. In our study, the influence of network density may impact perceptions about what the work of the CIO and corporate IT function should be, or what is the role of IT in business. The larger a network the lower the network density, because people have cognitive, emotional, spatial and temporal limits on how many social ties they are able sustain [17].

An organization consists of several social groups to which individuals are connected. Individuals are also connected to groups outside of their own social group through their weak ties [17]. Weak ties between social groups provide access to information and resources beyond those available in their own social group [16]. In our study, the significance of ties [17] may appear both through strong and weak ties. Strong ties describe information flow within a particular social group such as the executive committee members of the case company, including the CFO. Strong ties produce shared views [16]. Thus, each social group may have a different view about what the work of the CIO and corporate IT function should be, or what is the role of IT. Unless there are also weak ties between the social groups, this social mechanism to discuss differing views is missing. Differences in views could reflect the impact of strong ties in past organizational structures.

The structural hole construct [17] extends the importance of weak ties. A structural hole means that two social groups of a network do not have a tie and that the lack of the tie adversely influences information and resource flow. The underlying idea is that it is even more important that the different groups of a network are connected than what is the quality of a particular tie, i.e. is the tie weak or strong. Information, such as the beliefs about CIO work, can only flow through (strong or weak) ties.

Social embeddedness, defined as the interpenetration of economic and non-economic action, is the final construct discussed. Work related organizational performance objectives typically have a strong economic undertone. A company's ability to save IT cost through IT/IS consolidation or to carry out post merger business-IT integrations efficiently are examples of economic objectives. On the other hand, social life has a largely non-economic focus. Granovetter [17, p. 35] describes, "When economic and non-economic activities are intermixed, noneconomic activities affect the costs and the available techniques for economic activities." In our study, the influence of economic and non-economic activities may appear as the cumulative influence of current and past social groups and ties, i.e., mixes of beliefs.

\section{Methodology and the case}

We chose to use the longitudinal case study methodology and cover the period between the years 2010 and 2016 in the media company, later referred to as the "Group". We depict the impacts of two major punctuations on three particular persons within the Group: the Group CFO, "the CFO", the Group CIO, "the CIO", and the IT manager of the bookstore business unit, the "IT Manager". The IT Manager worked as the CIO of the bookstore company, which was merged into the Group as a new business unit after an M\&A transaction. These three persons represent different hierarchical layers of the Group as well as different social groups. In addition to them, 
we interviewed all other IT managers in the Group to create an understanding of how business interruptions impacted upon the equilibrium of tasks performed by the CFO, the CIO and the IT Manager prior and after punctuations. That is, we validated (triangulated) the stories of the CFO, the $\mathrm{CIO}$ and the IT Manager with other persons' stories.

The stance of our research is interpretative and we aimed to understand how individuals interpreted the order in their world [21, 4]. Consequently, we assumed that the knowledge of interviewees reflected their understanding of reality, both of which are in flux, and that possible gaps in knowledge are filled based on an individual's own understanding, experience, background and social network [2]. In this kind of qualitative study, interviews can have multiple interpretations [25]. All interpretations are affected by the stance of the actors - interviewees, researchers and article readers [32]. Each form of knowledge is partial and the strengths of one form of knowledge are at the same time the weaknesses of another form [40]. Nonetheless, we believe that the present research provides complementary insights for understanding the impact of business strategy induced interruptions upon the equilibria of sociotechnical elements in the CIO work of the three executives including the influences of perceptions about the roles of IT and the Group IT function.

We used semi-structured interviews and a questionnaire of business strategy changes during the years 2010-2016. The timeline of these changes was studied carefully by using a questionnaire in which questions of the timeline before, during and after interruptions were asked. We judged that a five to six year period is comprehensive and fulfils the validity needs of time units and time boundaries described by Street and Ward [38]. We did two rounds of interviews; on the first round we conducted eight interviews and on the second round three. Five of the first round interviews were used to validate the story events of the three key persons. Additionally, we interviewed the CIO a third time. The eight interviewees constituted the core of relevant executives and managers related to CIO work in the Group. In each interview we allowed sufficient time to discuss other issues if the interviewee so felt. Each interview was done using a projector showing all the questions to the interviewee. During the interview the researcher typed the interviewee's responses so that the interviewee saw immediately what was written. Typing responses during the interview slowed down discussion but gave the possibility to an interviewee to correct his/her responses at once. All interviews were also recorded and two researchers checked separately the accuracy of the written narratives from the recordings afterwards. The thus verified interview text was then sent to the interviewee and s/he had the possibility to change her/his responses. Four out of eight interviewees made some changes to the text at the first round. At the second round each interviewee accepted her/his written narratives of the $1^{\text {st }}$ and the $2^{\text {nd }}$ rounds, her/his part of Figure 3 and had the possibility to add insights to her/his story. Procedures described here were used to triangulate data, since no documents existed on how the CFO, the CIO and the IT Manager perceived IT, the corporate IT function and the influences of the punctuations. We think that the way the interviews were conducted added to the credibility of our interpretive qualitative research.

We selected the case company among those that had been interviewed already for another CIO study [9]. From that study we found a pair of CIOs who were parties on the opposite sides of a major M\&A transaction. More importantly both of them remained and still work in the Group five years after that M\&A. One of them was and still is the CIO of the Group and the other became the IT Manager for the bookstore business unit. We recognized this unique opportunity to collect data on how subjects felt the business interruptions and the roles of IT and the Group IT personally and socially. Hence, we decided to study one case company in depth as an alternative to our initial idea to investigate several cases.

There were two major business interruptions during the years 2010 - 2016: the M\&A transaction in 2011 and the decision to develop a shared business solution in 2015. At the beginning of the year 2010, the Group had two business units. They had been established as the outcomes of greenfield investments and M\&A transactions carried out prior to the year 2010. The prior 2010 M\&A transactions had impacted rather heavily on the tasks and the people of the centralized Group IT function headed by the CIO. A digital services business unit had been established to provide digital services to the customers of the Group. The idea was to nurture entirely new digital businesses within a separate business unit. Thus, the Group IT had no involvement in the IT of that business unit. In 2010, the bookstore company eventually purchased by the Group still belonged to another media company but was up for sale. In the pre-merger bookstore company, the then-current CIO was one of the company's executive committee members reporting to the CEO of the bookstore. In the Group, the CIO reported to the CFO and was not a Group executive committee member.

The Group conducted the acquisition of the bookstore company in late 2011. The CIO, the IT Manager and the two other IT managers with Group level tasks were involved full-time in the bookstore 
post-merger IT integration. From the business strategy point of view, the acquisition of the bookstore complemented the Group's value chain. From that moment onward, the value chain of the Group covered everything from the decision to publish (a paper or an electronic version of) a book through to its sale and delivery. This acquisition and merger was also considered as an important defensive strategic move. The purchase of the bookstore not only provided sales channels to markets but also secured the existence of those channels for the products of the Group. Financially, the acquisition was a significant transaction for the Group. The size of the bookstore was one third of the Group's size measured by revenue. Immediately after the M\&A transaction was closed, the Group nominated a new CEO to the newly established bookstore business unit from the Group. His task was to integrate the activities of the old and the purchased businesses and to bridge possible knowledge gaps.

M\&As continued after the year 2011, and cumulatively the Group had executed eight M\&As by the end of 2015. In 2014 the Group consisted of four business units. The chairman in the Group's board of directors changed in 2014. After that event the value chain concept was communicated even more strongly as the business strategy of the Group. On the other hand, business units concentrated on their own businesses and a business unit focus remained strong in their steering. Tension between the Group level value chain thinking and the business unit-driven "silo" thinking is important for understanding the results of our research. In 2013 and 2014, the Group disclosed record profits and high profits in 2015.

\section{Results}

\subsection{Group IT during the Years 2010-2016}

The bookstore business was novel for the Group and this impacted the post merger IT integration. The IT infrastructures of the two companies were integrated into the Group infrastructure within nine months. All vital information systems used to run the bookstore business remained intact, however, simply because no substitute systems existed. Retaining the bookstore IT function competences was also supported and no radical changes were carried out immediately. However, because both companies had a CIO and only one person could act as the Group $\mathrm{CIO}$, the then-current $\mathrm{CIO}$ in the bookstore company was transferred to an IT manager position in the newly established bookstore business unit. He told us: "We got the time to create a shared understanding about technology, people and structures. That was wise." Weak ties were given the time and possibility to become strong ties.

The other IT managers who worked in business units did not take part to the bookstore acquisition. They, however, told us that "this acquisition led the whole organization (=Group) to define in IT-sense what is done separately in business units and what is shareable Group level work". From a technology point of view, different business units use in some cases the same technology, such as a shared application, but the application could still be installed into each business unit as a separate instance.

The CIO was under pressure with growing workloads and projects. In 2013 a shared IT architecture framework was created by the Group IT. In 2014 this work was, however, frozen due to the objection from one business unit. In the bookstore unit, the IT Manager and the other executives continued to concentrate on optimizing the bookstore unit's processes. They co-operated with the Group IT only if that proved beneficial to the bookstore unit. During the same year (2014), all large infrastructure contracts were renewed and the cost level in the Group IT was for the first time lower than in earlier years. In 2014, the internal change of the bookstore unit was finally completed and co-operation at Group level started with the aim of seeking mutual benefits. At the end of 2014, the IT Manager suggested to establish a new shared function for online and book club businesses and in 2015 his proposal was accepted as a change project. The IT Manager was selected to lead this change project to unify the online and book club technology platforms. During the same year, M\&As continued and changes to the IT infrastructure began to take place.

As of 2016, even though the online and book club have been unified to a single function, the personnel still belong to the original business units. This has created complexities to the project mentioned above. The key issue is who owns the revenues as personnel still reside in two separate business units. Eventually, the IT Manager had to establish two separate technological solutions, one for the bookstore unit's online business and another for the book clubs. The complex organizational structures and unwillingness to seek synergies were the reasons behind this modification to the original plan of full unification.

\subsection{Interruptions and the equilibria of work}

Figure 3 illustrates how the two investigated business interruptions impacted the equilibria of work for the CFO, the CIO and the IT Manager. The timelines in the figure are split into four periods; a year before the (bookstore) M\&A, years just after the 
M\&A, years 2013-14 and years 2015-16. Each period describes the status of the equilibria as analysed from the first round interviews and as confirmed by the $\mathrm{CFO}$, the CIO and the IT Manager in the second round of interviews. The uppermost timeline is that of the CFO and it reflects the attitudes of the Group's executive committee and the board. The CIO's timeline, in the middle, is representative for the Group's IT function, and the IT Manager's timeline at the bottom for the (bookstore) business unit(s). The Leavitt model factors are marked as follows: Te equals technology, $\mathrm{P}$ equals people, Ta equals tasks and $\mathrm{S}$ equals structure. Thicker lines in red colour show factors and relations between factors that are unbalanced. Black colour factors and relations between factors are in equilibrium. The sizes of fonts depict the significance of the change in a factor. Despite interviewee confirmation, the colours, line widths and font sizes as well as structural gaps between the timelines are our interpretations about the data. A structural gap, for example between the $\mathrm{CIO}$ and the IT Manager during the period of years 2013-2014, means that communication ties concerning shared IT work were limited.

Figure 3 shows that the equilibria differed between the three persons even though they were in direct manager - subordinate relations. Why? It appears that the persons had different aspired-for equilibria of tasks, which reflected the deep structure [14] and strong ties [17] of their social groups. The CFO thought that only the bookstore M\&A had a strategic impact on the Group and his work. From the perspective of his social groups (the executive committee and the board), the equilibrium of tasks remained fairly balanced. $\mathrm{He}$ had to renew managerial reporting to reflect the Group's new organizational structure with the new bookstore business unit and the value chain thinking. As he was able to do that quickly after the M\&A, he achieved his new aspired-for equilibrium rapidly.

In contrast to the CFO, the CIO's work has changed significantly and been in constant flux during the six years our research covers. The bookstore IT infrastructure was integrated to the Group's IT infrastructure in 2012. In 2013, a logistics function was established within the Group IT. Besides these the small constantly occurring M\&A's impact the work in Group IT. All these changes increased the responsibilities of the Group IT function. The interviewed IT managers emphasized that the bookstore M\&A brought new processes and technologies to the Group and consequently increased the workload of the Group IT. During the last ten years the Group IT function had been reshaped several times. The headcount had dropped from 46 persons in 2006 to 25 persons in 2016 and the CIO felt constant pressure to save IT costs despite of all changes and increased responsibilities.

As Figure 3 shows, her world was anything but stable. Unified value chain, architecture and business-IT alignment driven IT describes her aspired-for equilibrium of tasks. In that world the Group IT would steer and control IT deployment in all the business units and functions of the Group to ensure effectiveness, cost-efficiency, consistency and interoperability. The CIO has been unable to reach her aspired-for equilibrium. She felt that pressures came constantly both from above (to save IT costs requested by the Group executives) and from below (to have fewer controls requested by the business units' IT managers).

From the IT Manager's perspective, his work was fairly balanced prior the bookstore M\&A, even though it was clear that the bookstore company would be sold as it fitted poorly to the business portfolio of the then-current owner. The IT Manager experienced major changes after the bookstore M\&A. His former IT department fell operationally under the control of the CIO and in 2012 the re-organized bookstore IT unit had to move physically to the same premises with the Group IT. There were both cultural and operative differences in, for example, project management and IT cost reporting. In the bookstore company, the IT department had been independent and was not accustomed to Group level controls. During the years 2013-2014 the IT Manager focused on processes and projects that increased the profitability of bookstore business unit. He felt that his equilibrium of tasks had reached a new balance, as he was able to focus again on the bookstore business with limited ties to the Group IT. He felt strongly that IT should be a part of business like it was in the bookstore company. That was his aspiredfor equilibrium.

\subsection{Role perceptions and social networks}

For this the two key findings are: The Group does not have a CIO with full responsibility over the entire deployment of IT. Secondly, there are clearly different perceptions about the (desired) roles of IT and the Group IT function. In our opinion these two findings are related. They reflect differences in the beliefs and norms [i.e. deep structure, 14] within the social groups of the Group and the lack of sufficient ties - i.e. interactive contemplative communication in the network - between these social groups. The lack of sufficient ties prevents the sharing of ideas and the establishment of shared understanding about the roles of IT, the Group IT function and work equilibria. 


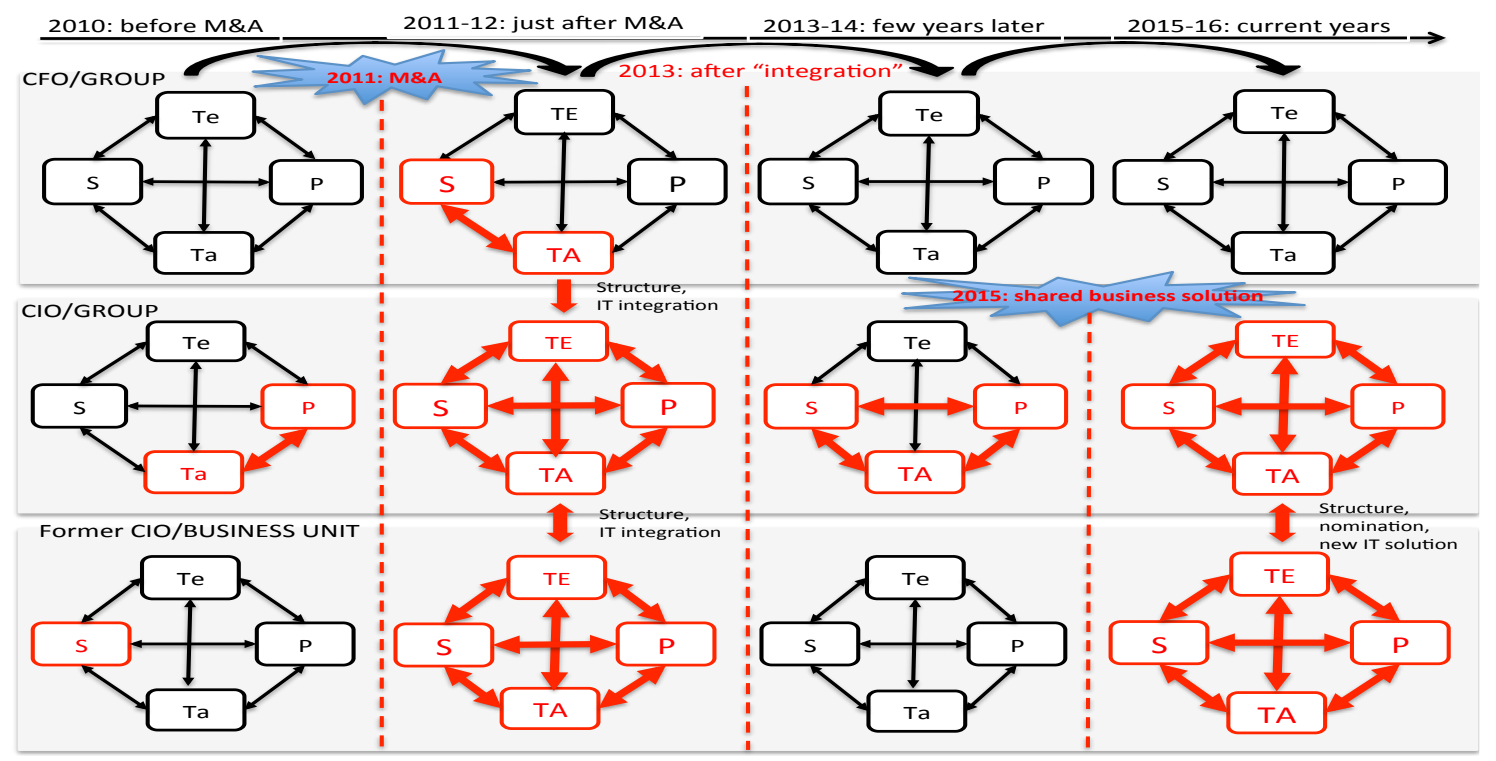

Figure 3. Business interruption impacts as seen by the CFO, the CIO and the IT Manager

The CFO defines the role of the Group IT as a support function. The deployment of IT to enhance the activities of the business units is seen as business technology, i.e., as the digitalisation of business. From this perspective it is understandable that the Group IT should not be involved in IT deployment, which happens in business units. On the other hand, the CFO notes: "The digitalisation has not gone forward as quickly as predicted." The CFO's social group consists of Group executives and the board.

The CIO reporting to the CFO would like to run the Group IT function as a business unit, which she is not really mandated to do. The Group IT has strict cost-efficiency targets and she has succeeded in lowering IT costs as mentioned earlier. According to her, the Group IT is responsible for the operative systems of business units and she has nominated IT managers to business units. Her organizational role as the governor of IT infrastructure and shared IT services limits her mandate to work with the digitalisation of business. On the other hand, the values and norms of her social group, the Group IT, influence her thinking on what the digitalisation of business means.

The IT Manager would like to run IT strictly aligned with the bookstore business. His perceptions about the desired role IT and the corporate IT function are closest to the digital strategy concept [3]. On the other hand, since he works in one business unit his values and norms reflect those of the bookstore business unit. Probably for this reason he is unhappy with the controls imposed by the Group (IT).
Comparisons of interviewees' narratives showed significant variations in their narratives. The influence of an interviewee's organizational position was obvious as well as the influence of the social group of an interviewee. Our empirical data suggests that a person enacts role behaviour according to the social group $\mathrm{s} / \mathrm{he}$ belongs. The constructs of the social network theory helped to understand the differences in the timelines of the punctuated equilibrium model shown in Figure 3. The social group of the interviewees impacted also their aspiredfor equilibrium of tasks and their perceptions about the roles of IT and the corporate (Group) IT function.

As a social world, the case company (Group) is characterized by power structures, vested interests, and limited resources to achieve the goals of the actors, who enact various organizational positions in the Group [25]. According to Loftus [26] the passage of time affects event recall ability, referred to as event memories. Each interviewee built her/his personal interpretation of the past. The organizational structure and the social groups one belong to created the borders of what is important to a person. According to the social network theory, a dense social group shares the norms and culture through strong ties. Even productivity and skills are shaped by those norms [17], which Gersick [14] calls deep structure. The sparsity of the network, lack of weak ties and structural holes offer a logical explanation for the differences in the views and aspirations of the three actors. The objectives of the Group IT function were economic. Yet, network ties were also social. 


\section{Discussion and Conclusions}

We discovered that business strategy-induced interruptions, punctuations, did unbalance the equilibria of work experienced by the CFO, the CIO and the IT Manager. After the punctuations, each of these three persons strived to reach a new personal equilibrium. They experienced changes in structure, technology, tasks and/or people and had to rebalance these factors to reach new equilibria. This finding is in line with previous studies $[13,28]$. The CFO reached a new equilibrium fairly quickly, whereas it took more time for the IT Manager. The CIO did not reach a new equilibrium during the six-year period investigated. We discovered also that there were differences in the perceptions of the three executives about the roles of IT and the Group IT within the case company as well as in aspired-for equilibria of work. This constitutes our answer to the first research question raised at the beginning of the article.

Differences between the deep structures [14] of the social groups to which the three persons belonged explained these differences together with the social mechanisms used to share ideas and other resources. High network density with strong ties within a social group, low network density with lack of weak ties together with structural holes hampering the sharing of ideas and other resources, and social embeddedness describing the economic and social nature of work, all helped to explain how the differences emerged in the equilibria of tasks and role perceptions. They also explained why these differences prevailed with such resilience. These constructs taken from Granovetter's social network theory appeared as highly useful additions to the punctuated equilibrium model. This is our response to the second research question.

For practitioners, we suggest that they would do well to pay attention to the layers of equilibria and to the social networks and their cohesion in the context of business strategy changes and other major interruptions. It needs to be understood that the sought-for equilibrium is not the same for every person in an organization's realm. Also the expectations and attitudes towards other units and functions are affected by cultural norms and are often unconscious and adversarial. We also learned from this case and from earlier CIO studies [e.g. 9, 35] that CIOs are under a great deal of stress due to constant changes in their work. CIOs often work with all units and functions in an organization and encounter conflicting demands and perceptions about IT with too few tools to cope with these demands. We suggest that this study may help practitioners to perceive the bigger picture.

Our findings suggest propositions, which are amenable to future research. Business applications and especially responsive Internet based IT-services for a company's clients seem to be highly politically charged. Questions, such as who is in charge and who has the power to decide the solution and the technology employed, are critical. We suggest that one field for future research could be company policies concerning technology decisions, and especially, the clarity of those decisions.

The weakness of our article is the case study in a one-company environment. However, we think that the initial setting of getting the CFO and both CIOs in an M\&A case interviewed and also having a longitudinal access to the three levels of the organization increases the credibility of the results substantially. This might not have been possible without the unique access to contacts we enjoyed.

\section{References}

[1] Agarval. R. \& Sambamurthy, V. (2002). Principles and Models for Organizing the IT Function MIS Quarterly Executive 1 (1), 1-16.

[2] Berger, P.L. \& Luckmann, T. (1966). The Social Construction of Reality. Random House, New York City, New York, United States.

[3] Bharadwaj, A., El Sawy, O.A., Pavlou, P.A. \& Venkatraman, N. (2013). Digital Business Strategy: Toward A Next Generation of Insights", MIS Quarterly 37 (2), 471-482.

[4] Burrel, G. \& Morgan, G. (2006). Sociological Paradigms and Organisational Analysis. Ashgate Publishing Ltd., Farnham, United Kingdom.

[5] BusinessDictionary.com (2016). From http://www. businessdictionary.com/definition.

[6] Cambridge Dictionary (2016). From dictionary. cambridge.org /dictionary/english/disruption.

[7] Chan, Y. E. \& Reich, B.H. (2007). IT Alignment: What Have We Learned? Journal of Information Technology 22 (4), 297-315.

[8] Coltman, T., Tallon, P., Sharma, R. \& Queiroz, M. (2015). Strategic IT Alignment: Twenty-Five Years On. Journal of Information Technology 30 (2), 91100.

[9] Dahlberg, T., Hokkanen, P. \& Newman, M. (2016). How Business Strategy and Technology Impact the Role and the Tasks of CIOs: An Evolutionary Model. International Journal of IT/Business Alignment and Governance 7 (1), 1-19.

[10] Doyle, G. (2016). Managing in the Distinctive Economic Context of Media in Managing Media Firms and Industries: What's So Special About Media Management? Lowe, G.F. \& Brown C. (eds.),Springer International Publishing, Cham, Switzerland, 175-188. 
[11] Eisenhardt, K.M. (1988). Agency and Institutional Theory Explanations: The Case of Retail Sales Compensation. The Academy of Management Journal 31 (3), 488-511.

[12] Gartner Inc. (2012). Gartner Market Databook, 2Q12 Update. From https:/www.gartner.com/doc/ 2070316/ gartner-market-databook-q-update.

[13] Gerow, J.E., Thatcher, J.B. \& Grover, V. (2015). Six Types of IT-Business Strategic Alignment: An Investigation of the Constructs and Their Measurement. European Journal of Information Systems 24 (5), 465-491.

[14] Gersick, C.J.G. (1991). Revolutionary Change Theories: A Multilevel Exploration of the Punctuated Equilibrium Paradigm. Academy of Management Review 16 (1), 10-36.

[15] Granovetter, M.S. (1973) The Strength of Weak Ties. American Journal of Sociology 78 (6), 1360-1380.

[16] Granovetter, M.S. (1983). The Strength of Weak Ties: A Network Theory Revisited. Sociological Theory 1 (1), 201-233.

[17] Granovetter, M.S. (2005). The Impact of Social Structure on Economic Outcomes. Journal of Economic Perspectives 19 (1), 33-50.

[18] Guillemette, M.G. \& Paré: G. (2012). Toward a New Theory of the Contribution of the IT Function in Organizations. MIS Quarterly 36 (2), 529-551.

[19] Henderson, J.C. \& Venkatraman, N. (1993). Strategic Alignment: Leveraging Information Technology for Transforming Organizations", IBM Systems Journal 32 (1), 472-484.

[20] Hilbert, M. \& Lopez, P. (2011). The World's Technological Capacity to Store, Communicate, and Compute Information. Science 332 (6025), 60-65.

[21] Holstein, J.A. \& Gubrium, J.F. (2005). Interpretive Practice and Social Action in The SAGE Handbook of Qualitative Research. Denzin, N.K. \& Lincoln, Y.S. (Eds.), Third edition, Sage Publications, Thousand Oaks, California, United States, 483-506.

[22] Johnson, G. \& Scholes, K. (1993). Exploring Corporate Strategy, Third edition, Prentice Hall International Ltd, Upper Saddle River, New Jersey, United States.

[23] Kaarst-Brown, M.L. (2005). Understanding an Organization's View of the CIO: The Role of Underlying Assumptions about IT. MIS Quarterly Executive 4 (2), 287-301.

[24] King, W.R. (1978). Strategic Planning for Management Information Systems. MIS Quarterly 2 (1), 27-37.

[25] Klein, H.K. \& Myers, M.D. (1999). A Set Of Principles For Conducting And Evaluating Interpretive Field Studies In Information Systems. MIS Quarterly 23 (1), 67-94.

[26] Loftus, E.F. (2005). Planting Misinformation in the Human Mind. A 30-year Investigation of the Malleability of Memory. Learning \& Memory learnmem.cshlp.org, Cold Spring Harbor Laboratory Press (12), 361-366.

[27] Lowe, G.F. \& Brown, C. (eds) (2016). Managing Media Firms and Industries: What's So Special About Media Management? Springer International Publishing, Cham, Switzerland, 1-20.

[28] Lyytinen, K. \& Newman, M. (2008). Explaining Information Systems Change: A Punctuated SocioTechnical Change Model. European Journal of Information Systems 17 (6), 589-613.

[29] McFarlan, F.W., McKenney, J.L. \& Pyburn, P. (1983). The Information Archipelago-Plotting a Course. Harvard Business Review 61 (1), 145-156.

[30] McKeown, I., \& Philip, G. (2003). Business Transformation, Information Technology and Competitive Strategies: Learning to Fly. International Journal of Information Management 23 (1), 3-24.

[31] Medina, M., Sanchez-Tabernero, A. \& Arrese, A. (2016). Contents as Products in Media Markets in Managing Media Firms and Industries: What's So Special About Media Management? Lowe, G.F. \& Brown C. (eds.), Springer International Publishing, Cham, Switzerland, 243-260.

[32] Myers, M.D. \& Newman, M. (2007). The Qualitative Interview in IS Research: Examining the Craft. Information and Organization 17 (1), 2-26.

[33] Napoli, P.M. (2016). The Audience as Product, Consumer, and Producer in the Contemporary Media Marketplace in Managing Media Firms and Industries: What's So Special About Media Management? Lowe, G.F. \& Brown C. (eds.), Springer International Publishing, Cham, Switzerland, 261-276.

[34] Orlikowski, W.J. (1996). Improvising Organizational Transformation Over Time; A Situated Change Perspective. Information Systems Research 7 (1), 63-92.

[35] Peppard, J., Edwards, C. \& Lambert, R. (2011). Clarifying the Ambiguous Role of the CIO. MIS Quarterly Executive 10 (1), 31-44.

[36] Sabherwal, R., Hirschheim, R. \& Goles, T. (2001). The Dynamics of Alignment: Insights from a Punctuated Equilibrium Model. Organization Science 12 (2), 179-197.

[37] Silva, L., \& Hirschheim, R. (2007). Fighting Against Windmills: Strategic Information Systems And Organizational Deep Structures. MIS Quarterly 31 (2), 327-354.

[38] Street, C.T. \& Ward, K.W. (2012). Improving Validity and Reliability in Longitudinal Case Study Timelines. European Journal of Information Systems 21 (2), 160175.

[39] Tushman, M. \& Romanelli, E. (1985). Organizational Evolution: A Metamorphosis Model of Convergence and Reorientation in Research in Organizational Behavior: An Annual Series of Analytical Essays and Critical Reviews (7), 171-222.

[40] Van de Ven, A.H. (2007). Engaged Scholarship, A Guide for Organizational and Social Research. Oxford University Press, Oxford, United Kingdom. 